\title{
Mechanical versus biologic valves: Clicking engines or quiet electrics or hybrids?
}

\author{
Lars G. Svensson, MD, $\mathrm{PhD},{ }^{a}$ and Eugene H. Blackstone, $\mathrm{MD}^{\mathrm{a}, \mathrm{b}}$
}

\footnotetext{
From the a Department of Thoracic and Cardiovascular Surgery, Heart and Vascular Institute, Cleveland Clinic, Cleveland, Ohio; and ${ }^{\mathrm{b}}$ Department of Quantitative Health Sciences, Research Institute, Cleveland Clinic, Cleveland, Ohio.

This work was supported in part by the Gus P. Karos Registry Fund, the David Whitmire Hearst, Jr Foundation, and the Kenneth Gee and Paula Shaw, PhD, Chair in Heart Research, held by Dr Blackstone.

Disclosers: L.G.S. was a stockholder of the bankrupt ValveXchange company, holds stock in CardioSolutions. He is also an unpaid member of the executive committee for Placement of Aortic Transcatheter Valves (PARTNER) trials I and II, and is an unpaid member of the executive committee of the COMMENCE trial, sponsored by Edwards Lifesciences. E.H.B. is an unpaid member of the executive committees of PARTNER II and COMMENCE, both sponsored by Edwards Lifesciences, leads the Cleveland Clinic branch of the PARTNER Publication Office, which carries out and publishes independent secondary analyses of PARTNER I data, and is supported by a grant to Cleveland Clinic from Edwards Lifesciences.

Received for publication Sept 4, 2015; accepted for publication Sept 5, 2015; available ahead of print Oct 15, 2015 .

Address for reprints: Lars G. Svensson, MD, PhD, Heart and Vascular Institute, Cleveland Clinic, 9500 Euclid Ave/Desk J4-1, Cleveland, OH 44915 (E-mail: svenssl@ccf.org).

J Thorac Cardiovasc Surg 2015;150:1396-8

$0022-5223 / \$ 36.00$

Copyright (c) 2015 by The American Association for Thoracic Surgery

http://dx.doi.org/10.1016/j.jtcvs.2015.09.032
}

An amusing tale is recounted about the late Dr Michael DeBakey, who supposedly took his Ferrari Dino to his mechanic for a valve repair job. On picking up the car, the mechanic said, "Dr DeBakey, I performed a much more complex operation on your car valves than you do on patients," to which Dr DeBakey replied, "Try doing it while the engine is running!" In regard to Dr DeBakey's reply, although it is true that the patient's life was still "running" in the sense of being sustained by a heart-lung machine, the heart nonetheless was stopped.

All mechanical heart valves click away noisily and need regular replenishments of warfarin to keep working, similar to cars that need oil changes. ${ }^{1}$ Now, of course, electric and hybrid vehicles are remarkably silent, with no noisy clicking engines, and do not need the same engine oils. Furthermore, these engines deliver better torque, are more efficient, and the energy and battery packs are renewable. In an interesting parallel, modern biologic heart valves are completely silent and more energy efficient than mechanical valves, can be easily replaced, with a low risk of death (between $0.5 \%$ and $2 \%$ ), and the heart does not need to be stopped in the case of valve-in-valve transcatheter valve replacement. ${ }^{2}$ Indeed, for each of the last 5 years of isolated aortic valve replacements $(\mathrm{n}=2160)$, mortality was $0.6 \%, 0.4 \%, 0.7 \%$, and $0.6 \%$, respectively (overall, $0.46 \%$ ).

The debate surrounding whether one should prefer a musical, noisy, oil-guzzling but reliable V12 Ferrari or V10 Lamborghini over a high-performing, governmentsubsidized, silent electric or hybrid car with a rechargeable/exchangeable battery (a car that can be hacked!) will

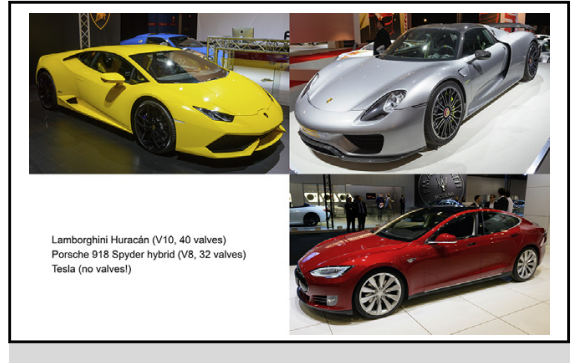

Clicking engines or quiet electrics or hybrids?

\section{Central Message}

Like car engines, heart valves are either noisy or silent, with differing attributes.

See Article page 1557.

See Editorial Commentary page 1568.

continue for years. Hence, we return to the debate about human valve repair and mechanical versus biologic valve replacement, particularly in view of those younger patients who demand the more active lifestyle provided by a repair or biologic valve and hope to receive a transfemoral valve-in-valve transcatheter replacement when the repair or bioprosthesis fails (Figure 1). ${ }^{1,2}$ Clearly, mechanical valves have better long-term durability, but it comes at the price of lifelong anticoagulation and higher adverse event rates. Indeed, Zellner and colleagues ${ }^{3}$ showed only a $40 \%$ 10 -year freedom from all events, including death.

Nevertheless, there is renewed interest in mechanical valves, lower anticoagulation levels (risk of bleeding complications vs thrombotic events, although the latter are more serious, is $\sim 2: 1$ ), perhaps less thrombogenic valves, and the hope that warfarin will be replaced by one of the newer anticoagulant agents. In our presentation at the American Association for Thoracic Surgery 2015 of 4 types of root procedures_-valve-preserving remodeling or reimplantation, biologic valve composite, mechanical valve composite, or allografts - we found that mechanical valve composite grafts did surprisingly well based on mortality and reoperation risk, and energy efficiency based on left ventricular mass regression. ${ }^{4}$ Furthermore, older-generation surgeons remember the remarkable Smeloff-Cutter ball valve, ${ }^{5}$ an invention sponsored by Jack Dempsey, Joe DiMaggio, and Jimmy Durante, which did not require anticoagulation and was very durable; we 
have taken out some that were in place for several decades. But of course they were neither silent nor very efficient. Allegedly because the valve did not go through a formal, modern Food and Drug Administration approval process, it was forced out of production.

What, then, of young patients requesting repairs or biologic valves (Figure 1)? Mitral valve repair is clearly the gold standard for degenerative valve regurgitation, but it is noteworthy that newer transcatheter-delivered devices are being promoted for its treatment, such as the Food and Drug Administration approval of mitral valve leaflet clips only for degenerative disease ${ }^{6}$ or the newer mitral valve spacer devices. ${ }^{7}$ Furthermore, previous open mitral valve repairs are not as good a platform for valve-in-valve transcatheter replacement, although the volume of fluid in the mitral valve spacer device can be adjusted by accessing the adjustment part under local anesthesia. The now defunct ValveXchange exchangeable leaflet valve (Denver, Colo) offered the option of remotely replacing valve leaflets after the initial open insertion, ${ }^{8}$ but the tsunami of transcatheter aortic valve replacement (TAVR) devices ${ }^{9,10}$ buried the chances of significant investment despite its early success and performance. Although aortic allografts and stentless valves for aortic valve replacement offer excellent efficiency and low energy loss, their durability is poor, failure often requires urgent repair, ${ }^{1}$ and as a platform for valve-in-valve TAVR, they are at increased risk of causing death from coronary occlusion or embolization, because the usual failure mode is severe aortic valve regurgitation (Figure 2). ${ }^{2}$

We recently published our late outcomes for 12,569 pericardial valve insertions. ${ }^{11}$ What was noteworthy is how well the valves held up in young patients, and high early postimplant pressure gradients were predictors of accelerated failure. In our TAVR program, particularly because many of our patients have come back for valve-in-valve TAVR, we have noted that the plastic band at the base of the Edwards Lifesciences PERIMOUNT 2700 model (Irvine, Calif) fractures or stretches, resulting in better hemodynamic pressure gradients than equivalently sized valves from other manufacturers, a serendipitous outcome for our patients. ${ }^{2}$ Indeed, a replacement valve with these features is being planned. Furthermore, as of August 2015, 884 patients have been enrolled in the Prospective Nonrandomized Multicenter Clinical Evaluation (COMMENCE) trial that is testing a biologic valve treatment (GLX, Edwards Lifesciences) that, according to animal studies, should have better long-term durability in younger patients and will then likely be applied to other areas with an excellent platform for valve-in-valve procedures, even it if is less likely to be required.

In conclusion, there has been an upsurge in biologic valve insertions, reflected in our own practice both for valve replacements (because of fewer mechanical valve insertions

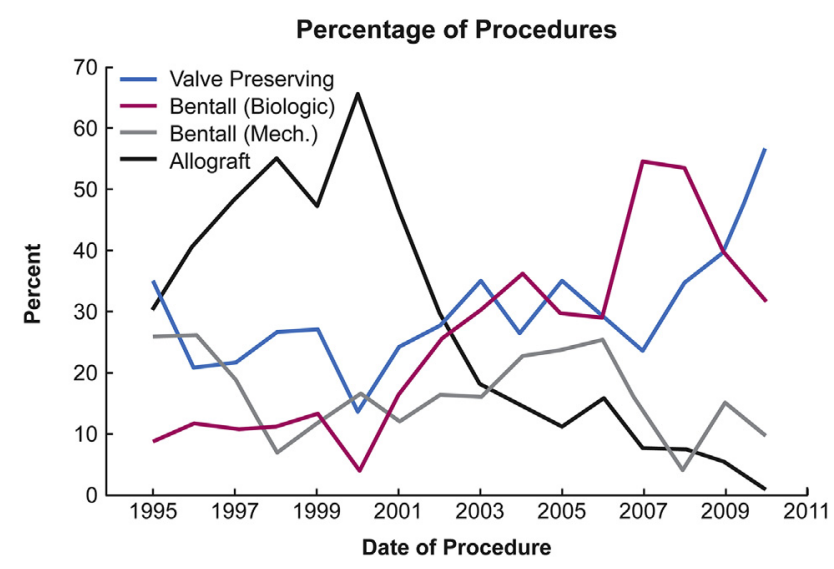

FIGURE 1. Changing approach to operations performed on the aortic root.

by patient choice and the hope of valve-in-valve TAVR ${ }^{12}$ ) and for biologic valve roots. Just like valved cars with V8/V10/V12 engines versus electric or hybrid vehicles, the options will be debated, but in the final analysis the decision will rest with what the patient is happiest with. The new, beautiful Porsche 918 Spyder hybrid holds the speed record around the Nürburgring Nordschleife track, the gold standard for car performance, but is it the most fun to drive or best in the long term? ${ }^{13}$ Gene loves bold pipe organ music, evidenced by a home built around more than 7000 clicking pipe valves, and both classic and modern high-quality mechanical valved cars, while Lars prefers a V8 (although a V10 or V12 would be nice), but his wife

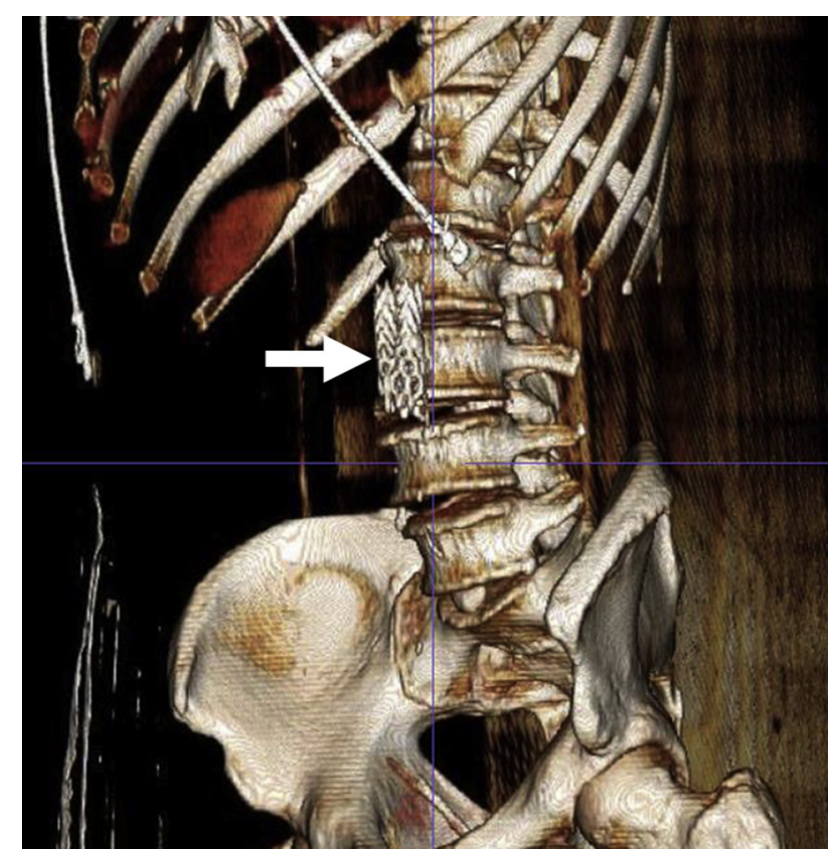

FIGURE 2. Computed tomography image of an attempted valve-in-valve insertion into a previous stentless valve replacement that has embolized to the distal aorta (arrow). 
loves her electric hybrid. Clicking valves or silent engines? It's all in the ears of the listener/receiver.

\section{References}

1. Svensson LG, Blackstone EH, Cosgrove DM III. Surgical options in young adults with aortic valve disease. Curr Probl Cardiol. 2003;28:417-80.

2. Tuzcu EM, Kapadia SR, Svensson LG. Valve design and paravalvular aortic regurgitation: new insights from the French registry. Circulation. 2014;129:1378-80.

3. Zellner JL, Kratz JM, Crumbley AJ III, Stroud MR, Bradley SM, Sade RM, et al. Long-term experience with the St. Jude Medical valve prosthesis. Ann Thorac Surg. 1999;68:1210-8.

4. Svensson LG, Pillai ST, Rajeswaran J, Desai MY, Griffin B, Grimm R, et al. Long-term survival, valve durability, and reoperation for four aortic root procedures combined with ascending aorta replacement. J Thorac Cardiovasc Surg. 2015 [in press].

5. Gometza B, Duran CM. Ball valve (Smeloff-Cutter) aortic valve replacement without anticoagulation. Ann Thorac Surg. 1995;60:1312-6.

6. Feldman T, Foster E, Glower DD, Kar S, Rinaldi MJ, Fail PS, et al. Percutaneous repair or surgery for mitral regurgitation. N Engl J Med. 2011;364:1395-406.
7. Svensson LG, Ye J, Piemonte TC, Kirker-Head C, Leon MB, Webb JG. Mitral valve regurgitation and left ventricular dysfunction treatment with an intravalvular spacer. J Card Surg. 2015;30:53-4.

8. Ebner A, Svensson GK, Chitwood WR, Sabik JF III, Svensson LG. Valve with exchangeable biologic leaflets. J Thorac Cardiovasc Surg. 2012;144: e13-4.

9. Greason KL, Pochettino A, Sandhu GS, Mathew V. Transcatheter aortic valve insertion in the nonagenarian patient. J Thorac Cardiovasc Surg. 2015;150: $720-1$.

10. Vahl TP, Borger MA. Transcatheter aortic valve replacement in nonagenarians. J Thorac Cardiovasc Surg. 2015;150:721-3.

11. Johnston DR, Soltesz EG, Vakil N, Rajeswaran J, Roselli EE, Sabik JF III, et al. Long-term durability of bioprosthetic aortic valves: implications from 12,569 implants. Ann Thorac Surg. 2015;99:1239-47.

12. Greason KL. Transcatheter aortic valve-in-stentless surgical aortic valve insertion: Hype or hope? J Thorac Cardiovasc Surg. 2015;150:99-100.

13. Car and Driver. 7-Down: Porsche 918 Spyder runs record-breaking 6:57 Nurburgring lap [blog post]. Available at: http://blog.caranddriver.com/7-down-por sche-918-spyder-runs-record-breaking-657-nurburgring-lap/. Accessed September $10,2013$. 